\title{
De-Centering the "West" in Cross-Cultural Philosophy: Philosophical Pedagogy in the Emory-Tibet Science Initiative
}

\author{
David M. Peña-Guzmán ${ }^{1 *}$ and Jessica Locke ${ }^{2}$ \\ ${ }^{1}$ School of Humanities and Liberal Studies, San Francisco State University, San Francisco, CA, United States, ${ }^{2}$ Philosophy \\ Department, Loyola University Maryland, Baltimore, MD, United States
}

This article explores the author's experience teaching in ETSI as an instance of a crosscultural intellectual encounter. It develops an account of cross-cultural encounters as defined by two moments: first, a moment of cultural shock when the encounter rebounds on the self, leading one to question one's assumptions about the world; and second, a moment of possibility where the self, after interrogating its own ways of thinking, can pivot to accommodate a detour from its past disciplinary and cultural habits. Here, the authors use the writings of the Argentinian feminist theorist María Lugones and the North American philosopher Frederick Elliston to clarify the nature of these moments.

Karsten Stueber

College of the Holy Cross, United States

Reviewed by: Anand Vaidya,

San Jose State University, United States

${ }^{*}$ Correspondence: David M. Peña-Guzmán davidmpena@gmail.com

Specialty section: This article was submitted to

Science and Environmental

Communication,

a section of the journal

Frontiers in Communication

Received: 19 June 2021 Accepted: 06 October 2021 Published: 05 November 2021

Citation:

Peña-Guzmán DM and Locke J (2021) De-Centering the "West" in CrossCultural Philosophy: Philosophical

Pedagogy in the Emory-Tibet

Science Initiative.

Front. Commun. 6:727760.

doi: 10.3389/fcomm.2021.727760
Keywords: cross-cultural philosophy, cross-cultural communication, Eurocentrism, Buddhism, ETSI

\section{INTRODUCTION}

In this article, we use our experience as faculty in the Emory-Tibet Science Initiative (ETSI) to reflect upon the epistemic significance of cross-cultural intellectual exchange. We examine a question we received multiple times during our 4 years teaching philosophy of science in ETSI: Do you think science will make you happy? The subtle yet profound critique of "Western" intellectual culture embedded in this question disrupted our habits of thinking in productive and meaningful ways. In our view, cross-cultural encounters such as the one enacted through this kind of question are defined by two moments: first, a moment of cultural shock when the encounter rebounds on the self, leading one to question one's assumptions about the world; and second, a moment of possibility where the self, after interrogating its own ways of thinking, can pivot to accommodate a detour from its past disciplinary and cultural habits. In what follows we use the writings of the Argentinian feminist theorist María Lugones and the North American philosopher Frederick Elliston to clarify the nature of these moments and consider how they showed up in our experience of teaching in ETSI.

\section{ETSI: A PRIMER}

In 2014, we joined the faculty of ETSI, a program "committed to bringing together the best of the Western and Tibetan Buddhist intellectual traditions for the creation, development and dissemination of knowledge and practices that will benefit humanity" (The Emory-Tibet Science 
Initiative 2020). ETSI was originally piloted in 2006, when His Holiness the XIV Dalai Lama invited scholars from Emory University in Atlanta, Georgia, to collaborate with the revered Library of Tibetan Works and Archives in Dharamsala, India. Seven years later, the second phase of the program was launched with the aim of implementing a comprehensive modern science curriculum at Sera, Gaden and Drepung monastic universities, with scholars from North American and European universities fanning across Tibetan settlements in South India, working closely with advanced monastic scholars and administrators to equip these universities to implement their own science education programs in situ. This historic and ambitious program offered courses in philosophy of science, biology, physics and neuroscience to advanced monastic scholars. The course we taught introduced these scholars to historical and contemporary debates in the philosophy of science as a way of priming their thinking for the concepts and ideas they would eventually encounter in the science courses that would follow. Some of the philosophical themes covered were falsification versus confirmation, inductive versus deductive reasoning, causation versus correlation, the nature of scientific observation, scientific realism versus antirealism, the social context of science, and the limits of science. The goal was to give our students a broad, albeit brief, introduction to the types of questions Western philosophers pose about scientific thinking.

Teaching this material in this context was profoundly enriching, to a large extent because our students-who were accomplished philosophers in their own right-approached the problems we introduced and questions we raised in ways that were novel to us. Indeed, before landing in India we were told by the monastic scholars who prepared us to "expect the unexpected" -- that is, to expect different styles of thinking, discussing, and debating than what we usually get from university students in the United States. After all, our monastic students had very advanced philosophical training -- in many cases much more advanced than ours -- but were unfamiliar with the basic principles of scientific practice that those teaching in Western-style universities may take for granted.

Of the unexpected, there was plenty. There were questions that took us some time to fully understand, as well as questions that we understood but didn't know how to answer. Here, we would like to focus on a specific question we encountered every year we taught in ETSI, a question that we now see as exemplary of both the challenges and promises of crosscultural philosophical encounters. Each summer, our students were eager to know, "Do you think science can make you happy?" While the question might seem misplaced or perhaps just a bit strange to a Western philosophical audience, there is a lot more packed into it than appears at first blush. Indeed, this question -- and the conversations it prompted among us, our students, and our translators -- models the transformative potential of crosscultural dialogue. By putting us in the position of questioning fundamental assumptions about our discipline and the
"Western intellectual tradition" more broadly ${ }^{1}$, this question forced us to take a detour from our disciplinary and cultural habits. In the possibility of this detour, we argue, lies the transformative epistemic power of cross-cultural intellectual encounters.

\section{WHAT'S IN A QUESTION?}

The straightforwardness of our students' question might make it easy to overlook the deep philosophical stakes beneath it. As we came to learn through conversations with our monastic students and translators, the question of whether a philosophical or intellectual tradition can deliver not only academic rigor but also soteriological transformation-that is, true, absolute happiness-was of paramount importance to them.

This is due, at least in large part, to the fact that Buddhism was founded on this kind of soteriological mission. The Buddha's first teaching after he attained enlightenment-known as the Four Noble Truths-was a diagnosis of the human condition as beset with suffering (Tibetan, Wylie: duk nghal) and an account of the path of ethical behavior, meditative practice and epistemological reorientation that leads to liberation from this suffering (see Thanissaro Bhikkhu 1993). The many Buddhist traditions that unfurled from that first teaching by the Buddha Shakyamuni some 2,600 years ago-including the many intricate philosophical exegeses, debates and commentaries of the Tibetan canon that comprise our monastic interlocutors' intellectual tradition-all maintain that soteriological aim as

${ }^{1}$ We use the term "Western intellectual tradition" advisedly. We are cognizant of the fact that there is, in fact, no single, monolithic "Western intellectual tradition" seeing as intellectual activity in Europe and North America has long been intercultural, multidisciplinary, and heterogeneous in method and orientation. This activity, moreover, has in no way been exclusively defined by scientism. For instance, since the 17 th century multiple Western philosophical lineages have been critical of the West's adoration of scientific rationality. In the 19th century, hermeneutics was founded upon the distinction between the "explanations" that science can furnish about the natural world and the broader "understanding" that only philosophy can give us about the meaning of human life and human affairs. Around the same time, German romanticism called for a return to nature and innocence largely out fear that the increasing "rationalization" of the world at the hands of science and technology would extinguish the creative, imaginative, and intuitive powers of the human spirit. Later, in the 20th century, other schools-such as phenomenology, existentialism, Critical Theory, pragmatism, as well as various stands of applied ethics - would similarly argue that one of the tasks of philosophy is to reflect upon the limits of science. Nonetheless, even if we recognize that not all Western intellectual activity is rooted in scientism, the majority of our students identified science as largely coextensive with Western thought itself. From their perspective, we were invited to their monastic universities as exponents of "Western" ways of thinking, especially scientific reasoning. Granted, this may have been a function of the structure of ETSI as a program that explicitly foregrounded science as the essential cross-cultural element to be integrated into monastic education. In any case, when we say that our cross-cultural philosophical encounter in ETSI made us rethink the "Western intellectual tradition," this is in part because through ETSI we were made newly aware of the way in which we were placed within the narrative surrounding that tradition by seeing ourselves as our interlocutors saw us. 
the core of the tradition. Even the most arcane and technical epistemological and metaphysical expositions of Buddhist philosophy ultimately come back to the goal of liberating sentient beings from suffering. It is this substantive understanding of happiness-as liberation from suffering rather than as worldly pleasure or mundane satisfaction-that informed our students' question, since they viewed the attainment of happiness as the ultimate purpose of the Buddhist tradition they have devoted their entire lives to systematically understanding ${ }^{2}$.

We were brought to India to impart the fundamentals of modern scientific thinking precisely because science has been identified-by His Holiness the XIV Dalai Lama and others-as a singular offering of Western intellectual culture, the lingua franca of the modern West ${ }^{3}$. Hence, when our students asked us whether we believed science could make a person happy, we came to understand that what they really wanted to know was whether we shared their soteriological mission and whether we had spent time reflecting upon the soteriological value of the intellectual method, discipline, and culture that we were there to teach. In short, they were asking: what, in the final analysis, is the value of the things on which you, as Westerners, spend so much of your time and cultural resources? Do those things liberate you from suffering? And if not-what is the final aim of what science does and what you do?

Of course, our students are not the first or the last to inquire into whether science (and, by extension, much of the standard approaches of European and North American intellectual culture) has the tools to address the most pressing human problems. For instance, the philosopher of science Nicholas Maxwell is known for his critique of the inadequacy of North American and European academia when it comes to meeting the enormous ethical and geopolitical challenges of the twenty-first

\footnotetext{
${ }^{2}$ Affirming this point, the social psychologist Heidi Levitt examines the monastic curriculum undergone by thirteen Tibetan Buddhist monks in Dharamsala, India, identifying the primary aim of Tibetan Buddhist monastic education as the cultivation of wisdom (as defined in Māhāyana Buddhist sutras on the perfection of wisdom, or prajña-paramitā) (Levitt 1999). Levitt's analysis focuses specifically on the nature of the wisdom that her subjects' education aimed to cultivate, but for our purposes, it is telling that in Buddhist epistemology, the perfection of wisdom is in fact co-emergent with the "mind of enlightenment" (Tibetan, Wylie: byang chub kyi sems). Wisdom and liberation are very closely tied together, if not inextricable. This points to the vast soteriological aims that contextualize Buddhist monastic education and even these monks' understanding of what it means to be "learned."

${ }^{3}$ To be clear, we do not abide by a reductive East-versus-West dichotomy according to which "the West" is the locus of scientific and critical rigor while "the East" is the cradle of mysticism and spirituality. For starters, there is a long history of intellectual traditions that have grown, and continue to grow, out of the West that view philosophy as driven primarily by the question of the good life. Moreover, many schools in East and South Asian philosophy rival Western philosophy of science in their rigor, precision, and commitment to logic. One of them is Buddhism itself. Another is the Indic philosophical system of Nyāya (from the Sanskrit for "method" or "judgment"), which foregrounds questions of knowledge (Pramāna Shāstra), the structure of inference (Tarka Shāstra), and the science of critical inquiry (Anvikșhi). All of this is to say that scientific thinking is not the sole purview of Western thought. Even so, the fact remains that underwriting the mission of ETSI was the belief that Western science is the key cross-cultural training required of the "twenty-first century monk."
}

century. Maxwell distinguishes the generation of knowledge from the imparting of wisdom. He argues that while Western spaces have proven their lot relative the first, they have failed tragically at the second, which incidentally is what this moment in our planet's history so desperately needs. On his view, Western intellectual culture teaches facts that allow one to identify the most effective means to reach an end, but it neglects to impart the ethical orientation that enables one to reflect upon the ends themselves. Maxwell makes an urgent call for a revolution in Western academia, reorienting its goals from the acquisition of knowledge to the cultivation of wisdom (Maxwell 2007; 2012; 2014). Although he almost surely does not have an aim on par with Buddhist soteriology in mind as the ultimate outcome of what he calls wisdom-inquiry, his point nonetheless resonates with the gentle but precise critique we heard from our students that as far as they could tell, for all its accomplishments, North American and European intellectual culture-and this includes science and philosophy of science-does not seem to be working toward what are actually the only questions that really, truly matter.

\section{THE EPISTEMOLOGY OF CROSS-CULTURAL DIALOGUE}

Although our monastic students' question and Maxwell's critique both interrogate the soteriological stakes of science and technology, inasmuch as these critiques-rightly or wrongly-both identify science as the predominating force in European and North American thought, we take their critique not only as a challenge to science but also to Western academic culture generally, including the practice of our own discipline of philosophy. Being faced with such a simple but profound question as whether science can make a person happy (in the substantive, soteriological sense) prompted us to re-examine the fundamental values that undergird our work as philosophers. By drawing into relief an unexamined premise of our profession and, indeed, our identities as North American academics, this kind of cross-cultural encounter dislodged our habits of thinking in important ways. To analyze the epistemology of that moment, in this section we briefly turn to the philosophers María Lugones and Frederick Elliston, who provide conceptual tools for describing the epistemic impact of cross-cultural philosophical exchange. Their concepts-of "world traveling" in Lugones and of the dialogic model of philosophical contact in Elliston-elucidate the epistemic significance of how our students' inquiry disrupted, disoriented, and ultimately enriched our thinking about the nature of our own philosophical activity.

The feminist philosopher María Lugones coins the term "world-traveling" to describe the experience of entering into genuine dialogue with those who do not share our perspective and making a concerted effort to see the world as they see it (Lugones 1987). World-traveling shifts our epistemic frame of reference as we catch a glimpse into "what it is to be them and what it is to be ourselves in their eyes" (Lugones 1987, 17). By familiarizing us with the strange and by estranging us from the familiar, she suggests, world-traveling stands to disrupt even our oldest, most sedimented patterns of thought. Lugones contrasts world-traveling with what the feminist theorist Marylin Frye calls "arrogant perception," a mode of relating 
to others whereby one instrumentalizes them by pressing them through the screen of one's preconceived notion of who they are. In arrogant perception, one "grafts the substance" of another person onto oneself, limiting their singularity (Lugones 1987, 4). Although Frye originally used this concept to name how men perceive women under patriarchy, Lugones reminds us that arrogant perception occurs along cultural lines as well, fostering in members of a dominant culture a dehumanizing indifference to the worlds of others (or an interest motivated by a will to master). By contrast, world-traveling gives way to playful curiosity about the lives of people who inhabit worlds different from our own, a curiosity that, by allowing us to momentarily see ourselves through new eyes, makes possible a more meaningful bond between self and other.

If Lugones' view of world-traveling clarifies the epistemic impact of being made strange to ourselves through an encounter with another way of thinking, the work of the philosopher Frederick Elliston highlights the importance of critically reflecting upon the intentions that philosophers hold when fostering philosophical conversations in unconventional spaces (Elliston 1983) ${ }^{4}$. He notes that, since the 1950s and 1960s, philosophers in North America have been "bringing philosophy" into a variety of unconventional spaces: "hospitals, clinics, old age homes, government agencies, high schools, private industry, independent research centers, prisons, police academies, and counselling centers" (Elliston 1983, 197). Elliston argues that there are two prevailing models for how philosophers tend to position themselves in these non-traditional settings. On the "missionary" model, philosophers are proselytizers who arrive in new spaces with the express intention of initiating "the locals" into their way of thinking. This model treats philosophers as subjects whose epistemic and moral authority is absolute-or at least unrivaled by that of their interlocutors-and whose task it is to enlighten, but not be enlightened by, those they might encounter. The counterpoint to the missionary model is the "social scientific" one, which assumes that philosophers can enter new spaces wholly undetected and leave them in the same condition in which they found it. Rooted in the scientific fantasy of the observer who sees everyone but is seen by no one, this model ignores how the observer is always an influence, a contaminant that alters the dynamics of the object they seek to analyze ${ }^{5}$. Despite their differences, Elliston says, both of these models share one fundamental error: they assume that the philosopher enters into these spaces of "otherness" either to change or to observe their interlocutors, but never to be changed by them.

\footnotetext{
${ }^{4}$ Although Elliston's article deals not with cross-cultural philosophical encounters but with philosophical conversations with non-academic interlocutors in non-academic (but still Western) settings, his line of inquiry provides a useful framework for analyzing our experience doing philosophy cross-culturally in ETSI by discussing a different form of world-crossing that is still relevant to understanding cross-cultural philosophical encounters

${ }^{5}$ As Elliston puts it: "Social scientists frequently decide to adopt a posture of non-interference. Because their overriding commitment is to the pursuit of truth, they seek to minimize the extent to which their presence alters the situation they wish to observe. Missionaries on the other hand typically adopt just the opposite stance: they take part in the affairs of others in order to lead them from their evil ways. Their ultimate goal is to save their souls, and they exercise all their personal skills and resources to this end" (Elliston 1983, 199).
}

Elliston ventures a third possibility for how philosophers who depart from the manicured confines of the Western university can approach their interlocutors: a "dialogic" model of positioning oneself in relation to others without assuming the supremacy of the self. Although he does not develop it in detail, Elliston claims that the defining feature of the dialogic model is that it "expands one's perspective to include others" (Elliston 1983, 201). On our reading, those who embrace this dialogic approach to cross-cultural communication recognize the limits of their perspective and strive to see things from the perspective of others to the extent that this is humanly possible (and in a manner reminiscent, in our view, of Lugones' world-traveling). Rather than assuming a position of epistemic or moral authority over others, dialogic philosophical pedagogues question their faith in their own epistemic and moral standing and are "brave enough to admit [their] biases and limits" (Elliston 1983, 202-203) ${ }^{6}$. This kind of dialogic encounter, Elliston insists, precludes pontification and requires careful listening ${ }^{7}$.

Together, Lugones' concept of world-traveling and Elliston's dialogic model of philosophical conversation underscore what we stand to gain from genuine cross-cultural encounters. When we venture outside of our habitual, culturally familiar paradigms, we are allowing ourselves to be made strange to ourselves. Seeing ourselves and our ways of thinking and being through a new lens, with a different sense of freshness and clarity, we can appreciate dimensions of ourselves that had disappeared from view and escaped our explicit attention. In other words, we can know ourselves-including our epistemic gaps, assumptions, and biases-more fully. Meanwhile, the model of a dialogic encounter illustrates the necessity of entering into novel philosophical spaces with the expectation of being changed by them. In our case, as ETSI instructors, avoiding the errors of the missionary and social-scientific models means approaching the encounter in a spirit of mutuality and receptivity, knowing that the integrity of that encounter rests upon our willingness to be decentered, disoriented, and ultimately enriched by the dialogue that ensues.

\section{CONCLUSION}

All of this speaks to what we argue is an essential component of cross-cultural philosophical dialogue, which is a readiness to accommodate detours from our own disciplinary and cultural habits. Cross-cultural dialogues are not a neutral "sharing of

${ }^{6}$ Gouinlock (1979) similarly notes that as philosophy educators "we must recognize our limitations" (48).

${ }^{7}$ Vaidya (2015) makes a similar argument. Arguing that comparative philosophy would be well served by adopting a directional shift toward public philosophy, he claims that public philosophy can take two modes: the "philosophy-to-public" direction, in which philosophers enter nonacademic spaces for the benefit of the public; and the "public-tophilosophy" direction, in which members of the public take up philosophy in a public space for the benefit of all. While the "philosophy-to-public" direction resembles Elliston's "missionary" approach, the "public-tophilosophy" direction "assumes that philosophy as a discipline could require directional navigation from the public" and "recognizes that for philosophy to evolve in a relevant and meaningful way over time it must not only be prepared to analyze for, but also to attend to" (Vaidya 2015, 5, 39). See also Vaidya $(2012 ; 2014)$. 
information," much less a "gift" from Western academics to uninitiated Others. Rather, they are opportunities to be displaced, disoriented and thereby transformed. Epistemic events like these necessarily rebound back upon all those involved in the conversation, unseating the fundamental assumptions that underwrite the conversation itself. For us, being willing to adopt our students' critical perspective about the nature and goals of science-and even our training in Western philosophy-allowed us to appreciate more holistically a subtle critique of the values of the Western intellectual culture in which we were trained, putting necessary and fruitful pressure on our own thinking about what philosophy is and is for.

It should be noted that the question that we faced repeatedly in ETSI-Do you think science can make you happy? - did change us, prompting us to deepen our understanding of what it is we hope to impart through our philosophical practice. Although we hardly would adopt a stance of guru or liberator as philosophy instructors on the model of a Buddhist teacher, we do take seriously the challenge that philosophy should meaningfully enrich the inner lives of those who participate in it, actually

\section{REFERENCES}

Bhikkhu, T. (1993). "Dhammacakkappavattana Sutta: Setting the Wheel of Dhamma in Motion.” Available at https://www.accesstoinsight.org/tipitaka/ sn/sn56/sn56.011.than.html.

Bruya, B., and Ardelt, M. (2018). Fostering Wisdom in the Classroom, Part 1. Teach. Philos. 41 (3), 239-253. doi:10.5840/teachphil201882889

Elliston, F. (1983). Introduction. Teach. Philos. 6 (3), 195-204. doi:10.5840/ teachphil19836349

Gouinlock, J. (1979). The Moral Value of a Philosophic Education. Teach. Philos. 3 (1), 37-49. doi:10.5840/teachphil19793121

Lugones, M. (1987). Playfulness, "World"-Travelling, and Loving Perception. Hypatia 2 (2), 3-19. doi:10.1111/j.1527-2001.1987.tb01062.x

Maxwell, N. (2007). From Knowledge to Wisdom: A Revolution for Science and the Humanities. 2nd edition. London: Pentire Press.

The Emory-Tibet Science Initiative (2020). Mission. Available at https://tibet. emory.edu/mission.html.

Vaidya, A. J. (2015). Public Philosophy: Cross-Cultural and Multi-Disciplinary. Comp. Philos. 6 (2), 35-57. doi:10.31979/2151-6014(2015).060206

Vaidya, A. J. (2014). How Universities Can Help Create a Wiser World: The Urgent Need for an Academic Revolution. Exeter: Imprint Academic. cultivating wisdom rather than simply leading to the accumulation of knowledge 8 . This means that we, as philosophy professors, should seek at the very least to serve as inviting guides to our students, aiming to foster wisdom in our students and help them orient themselves in the direction of a better life.

\section{DATA AVAILABILITY STATEMENT}

The original contributions presented in the study are included in the article/Supplementary Material, further inquiries can be directed to the corresponding author.

\section{AUTHOR CONTRIBUTIONS}

All authors listed have made a substantial, direct, and intellectual contribution to the work and approved it for publication.

Vaidya, A. J. (2012). "Wisdom: Object of Study or Basic Aim of Inquiry," in The Scientific Study of Personal Wisdom. Editors M. Ferrari and N. Weststrate (New York: Springer).

Conflict of Interest: The authors declare that the research was conducted in the absence of any commercial or financial relationships that could be construed as a potential conflict of interest.

Publisher's Note: All claims expressed in this article are solely those of the authors and do not necessarily represent those of their affiliated organizations, or those of the publisher, the editors and the reviewers. Any product that may be evaluated in this article, or claim that may be made by its manufacturer, is not guaranteed or endorsed by the publisher.

Copyright (C) 2021 Peña-Guzmán and Locke. This is an open-access article distributed under the terms of the Creative Commons Attribution License (CC $B Y)$. The use, distribution or reproduction in other forums is permitted, provided the original author(s) and the copyright owner(s) are credited and that the original publication in this journal is cited, in accordance with accepted academic practice. No use, distribution or reproduction is permitted which does not comply with these terms.
${ }^{8}$ In an article published in 2018 in Teaching Philosophy, the philosophers Brian Bruya and Monika Ardelt express a similar sentiment regarding the importance of using philosophical education to inculcate wisdom. They identify five components of wisdom pedagogy: challenging beliefs, prompting the articulation of values, encouraging self-development, encouraging self-reflection, and cultivating moral emotions (Bruya and Ardelt 2018). Bruya and Ardelt, however, note that these are precisely what is often missing from traditional philosophical instruction, especially in formal, academic settings. "Perhaps reflecting a general uncertainty about the practicality of fostering wisdom in formal education, the existing literature on theories of wisdom pedagogy is not extensive," they say (Bruya and Ardelt 2018, 240) 